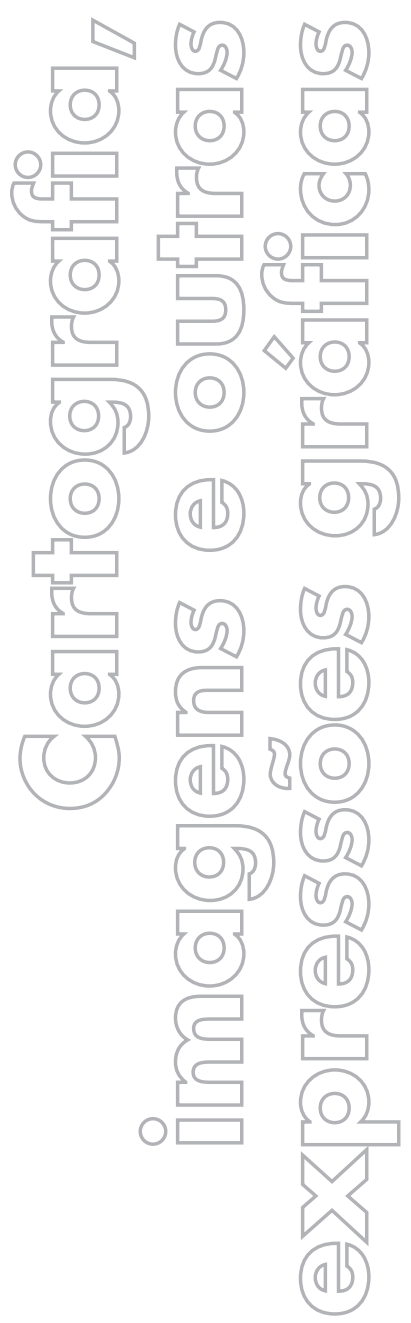

\section{revista}

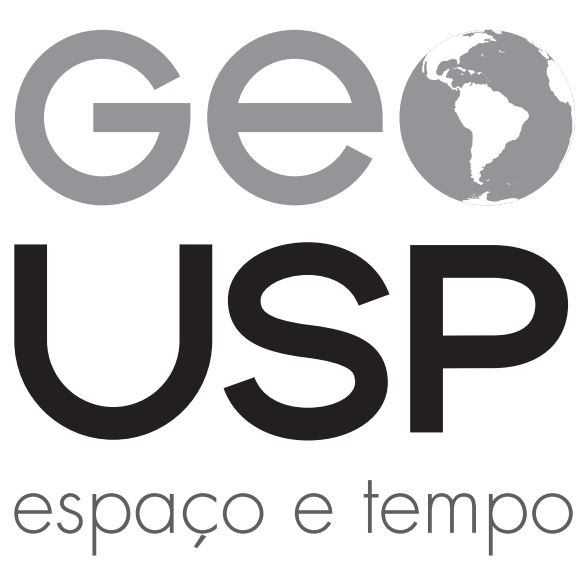

Volume 19, no 1 (2015)

\title{
Representações de fluxos aéreos
}

Hervé Théry CNRS-Creda

p. $160-165$

Disponível em:

http://www.revistas.usp.br/geousp/index

Como citar:

THÉRY, H. Representações de fluxos aéreos. GEOUSP Espaço e Tempo, São Paulo, v. 19, n. 1, p. 160 - 165, 2015.

\section{$(\mathrm{cc}) \overline{\mathrm{EY}}$}

Este artigo está licenciado sob a Creative Commons Attribution 3.0 License. 


\section{Representações de fluxos aéreos}

O IBGE (2013) lançou a publicação Ligações Aéreas 2010, parte do projeto Redes e fluxo do território, em papel (ISBN 978-85-240-4286-7) e em CD-Rom (ISBN 978-85-2404287-4). A equipe, ' coordenada por Claudio Stenner, indica nas notas técnicas que:

[...] a partir de informações presentes no Anuário do transporte aéreo 2010, da Agência Nacional de Aviação Civil - Anac, foi composta uma matriz de ligações origem-destino do transporte aéreo entre 135 cidades brasileiras com aeroportos, para o ano de 2010. Essa informação ficou restrita ao território nacional e aos voos regulares registrados na Anac, e estão decompostos em transporte de passageiros e carga [...]. a matriz é composta por 877 pares de ligações, perfazendo um total de 71750986 de passageiros transportados e mais 434 mil toneladas de carga [...] também foram levados em conta os dados históricos disponibilizados on-line pela Anac desde 1972.

Como o IBGE tem a elegância de pôr à disposição dos usuários os dados elaborados para o trabalho, usou-se a base de dados depositada em formato Excel no site do Instituto ${ }^{2}$ para tentar representações diferentes daquelas - bem expressivas - presentes no trabalho, usando a liberdade acadêmica para fugir dos padrões cartográficos do organismo oficial e um recurso muito provavelmente ausente da caixa de ferramentas da equipe, o software francês Cartes et Données. ${ }^{3}$

O mapa (Figura 1) produzido pela opção "fluxos" do software a partir dos custos de viagem (a imagem produzida com os tempos de viagem é muito similar) dá uma imagem sintética que destaca bem as ligações densas e de baixo custo entre as cidades litorâneas (em verde), completado por um eixo na direção noroeste. As regiões periféricas, ao contrário, são marca-

\footnotetext{
Adma Haman Figueiredo, Celso Guilherme de Souza Silva (estagiário), Claudio Stenner, Cleber de Azevedo Fernandes, Geovanna Vera Cruz Porto Batista (estagiária)Marcele Borges dos Santos (estagiária), Marcus Vinicius Siqueira de Oliveira (estagiário), Paulo Wagner Teixeira Marques, Ronaldo Cerqueira Carvalho, Schaiane Nogueira Ouverney Barroso e Tuani Cristina Lima de Souza (estagiária).

2 ftp://geoftp.ibge.gov.br/redes_e_fluxos_do_territorio/ligacoes_aereas/bases_de_dados/xls/, de onde se pode também baixar gratuitamente o trabalho em formato pdf.

3 Apresentado no site http://www.articque.com/solutions/cartes-et-donnees/ (em francês) ou http://www.articque. com/language/en/ (em inglês), o programa GéoCampus permite acesso a esse software profissional, normalmente vendido por 2.680 euros ( $\mathrm{R} \$ 9.250,00$ ), gratuito para estudantes e com preço muito reduzido para pesquisadores e professores (http://www.articque.com/geocampus/ ou http://www.articque.com/geocampus-en/).
} 
das por ligações muito mais caras (cores salmão e vinho no mapa), em boa parte escondidas atrás dos fluxos verdes, consequência negativa do lado sintético - 877 pares de ligações numa única imagem - mas complexo da imagem.

Uma saída é aplicar filtros aos dados, seja de custo, seja de origem geográfica dos fluxos. A Figura 2 seleciona os eixos onde as passagens são mais baratas, reforçando o que aparecia na Figura 1, e os mais caros que saem do oeste da Amazônia (especialmente de Tabatinga) ou do extremo sul (especialmente de Pelotas).

A Figura 3 foi produzida juntando (no software gráfico Adobe Illustrator) numa única imagem os mapas obtidos filtrando os dados por cidade de origem, usando para todas a mesma discretização dos custos entre os mais baratos (em verde) até os mais proibitivos (em vermelho). Aparecem então semelhanças entre as figuras criadas pelas setas divergentes de cidades vizinhas, "famílias" que a Figura 4 organiza por região já que o fator principal que rege a sua forma parece ser a sua localização, apesar de todas ser sutilmente diferentes em função de suas peculiaridades.

\section{Figura 1 - Fluxos aéreos em 2010, visão global}

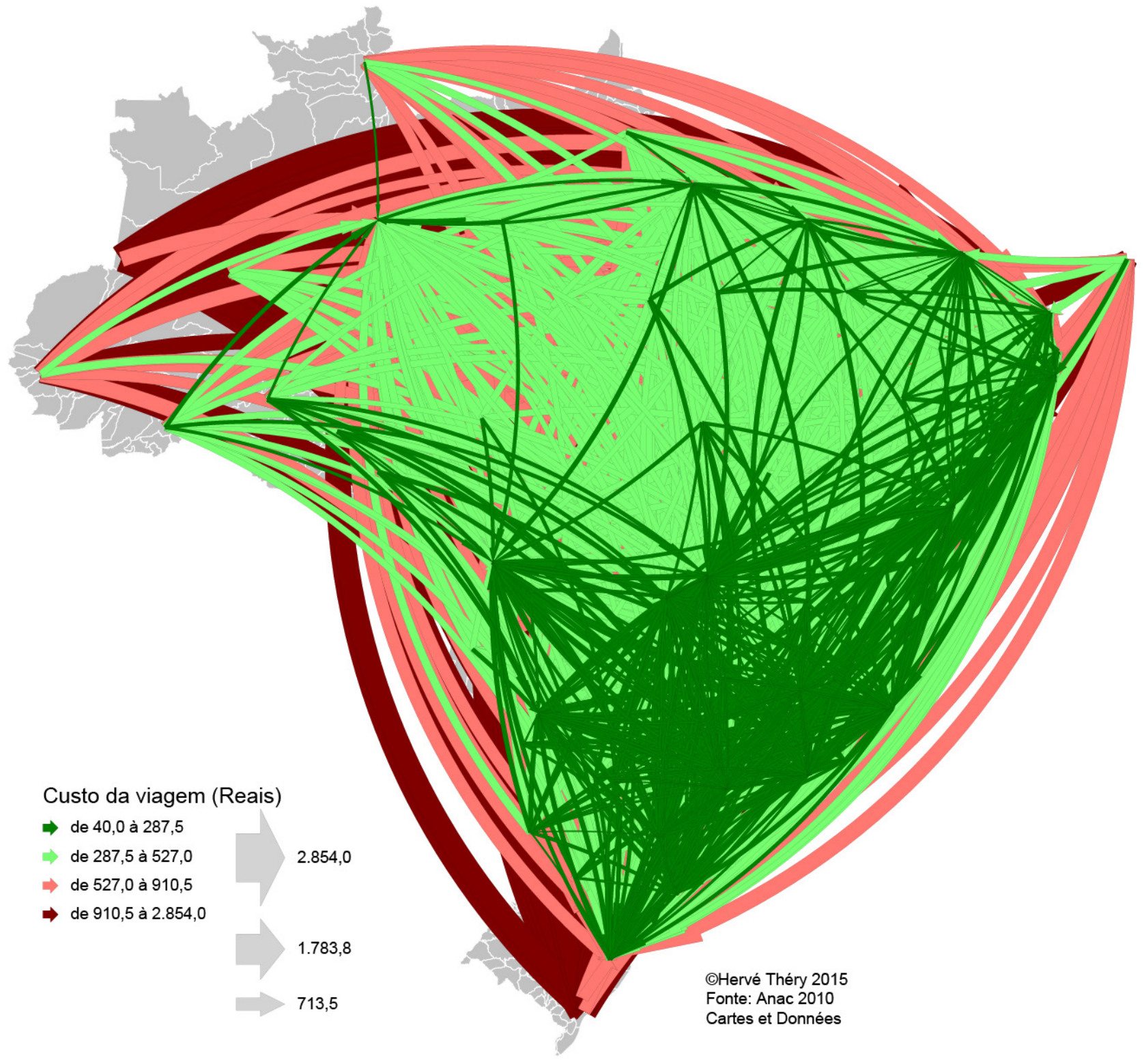


Figura 2 - Fluxos aéreos em 2010, os mais baratos e os mais caros
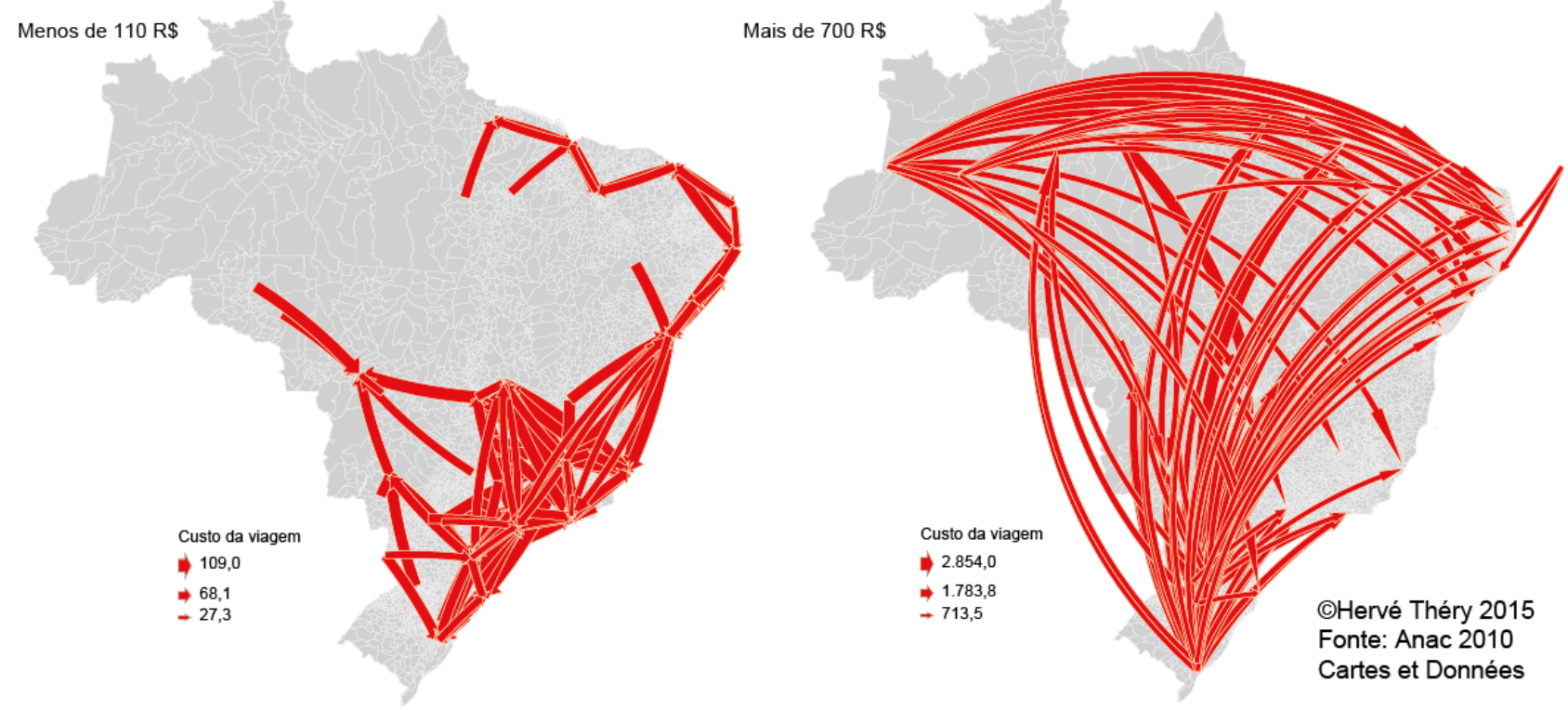

Figura 3 - Fluxos aéreos em 2010, visão diferenciada por cidade

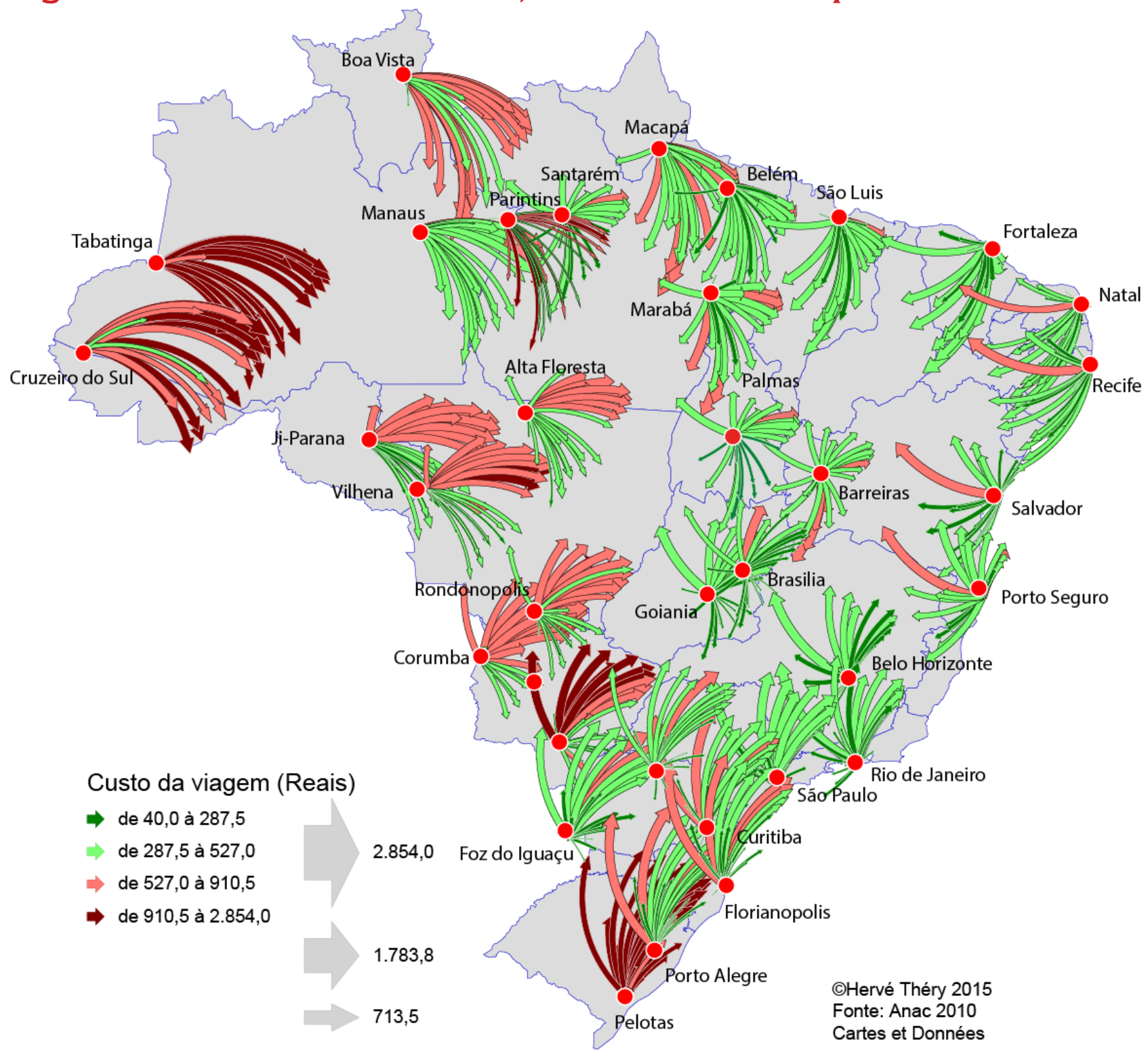


Figura 4 - Fluxos aéreos em 2010, famílias regionais de formas

\section{Amazônia occidental}

Amazônia oriental
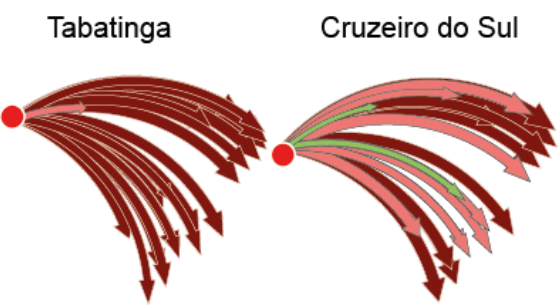

Manaus

Parintins
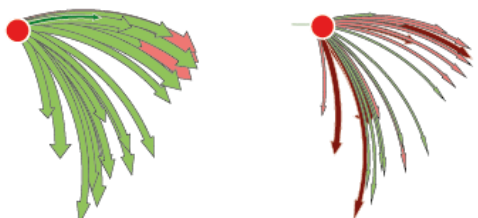

\section{Centro-Oeste}

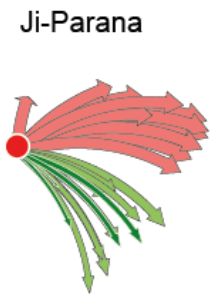

Corumba

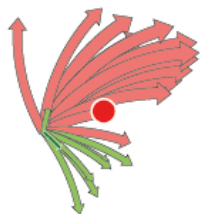

\section{Centro}

Barreiras

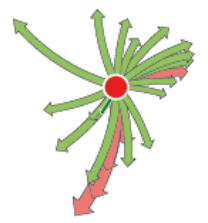

Brasilia

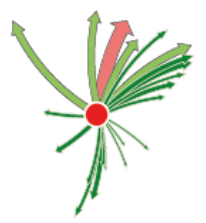

Sul

Porto Alegre

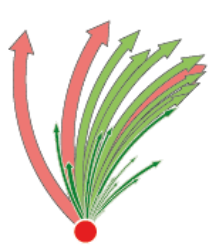

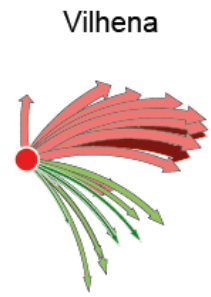

$$
\text { Rondonopolis }
$$
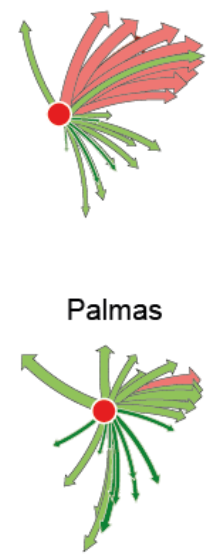

Goiania
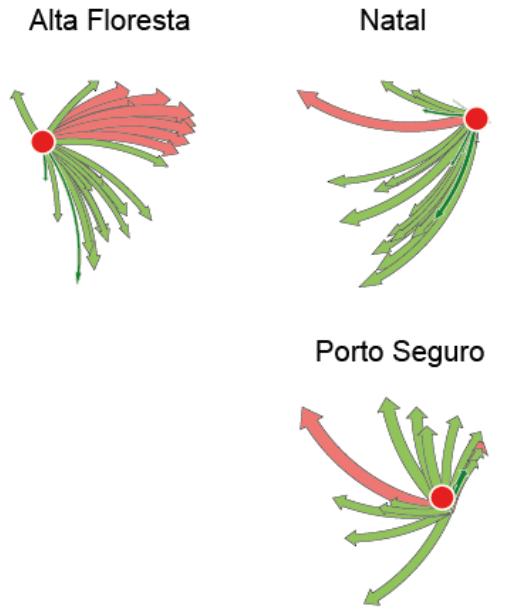

São Paulo
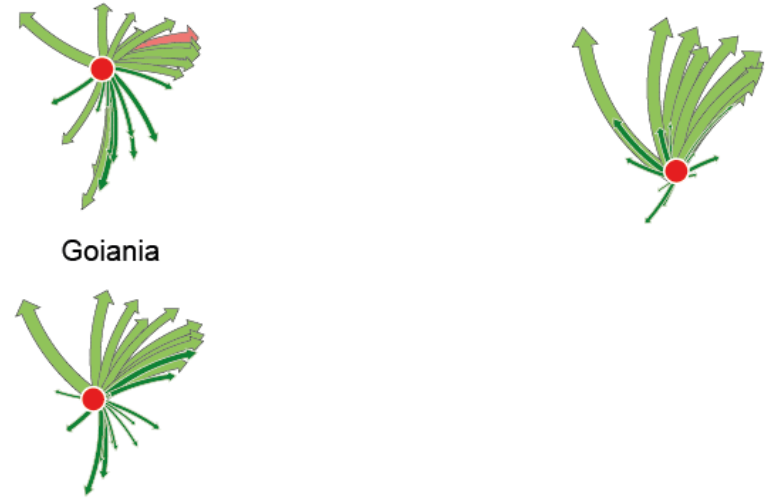

Florianopolis

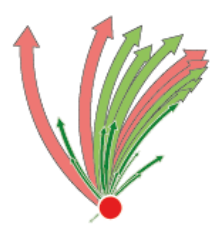

Foz do Iguaçu

Curitiba
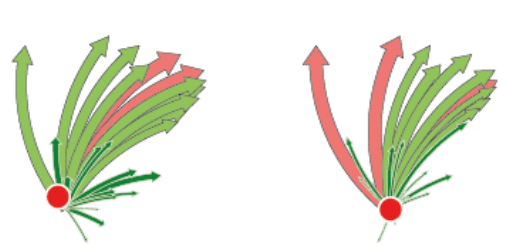

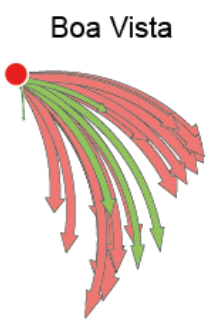

Belém

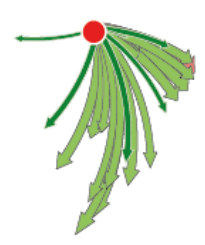

Santarém

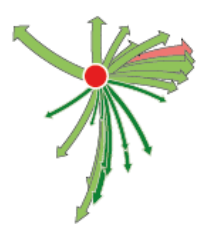

Fortaleza

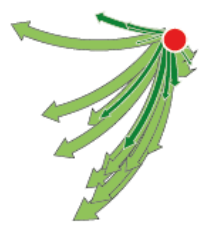

Salvador
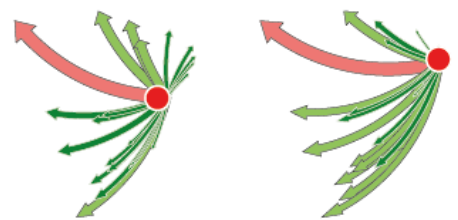

Sudeste

Rio de Janeiro

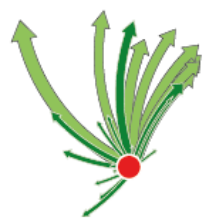

Belo Horizonte

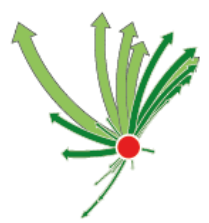

Custo da viagem (Reais)

$\Rightarrow$ de 40,0 à 287,5

$\Rightarrow$ de 287,5 à 527,0

$2.854,0$

$\Rightarrow$ de 527,0 à 910,5

$\Rightarrow$ de 910,5 à $2.854,0$

$1.783,8$

713,5 
Figura 5 - Fluxos aéreos, evolução entre 1972 e 2010
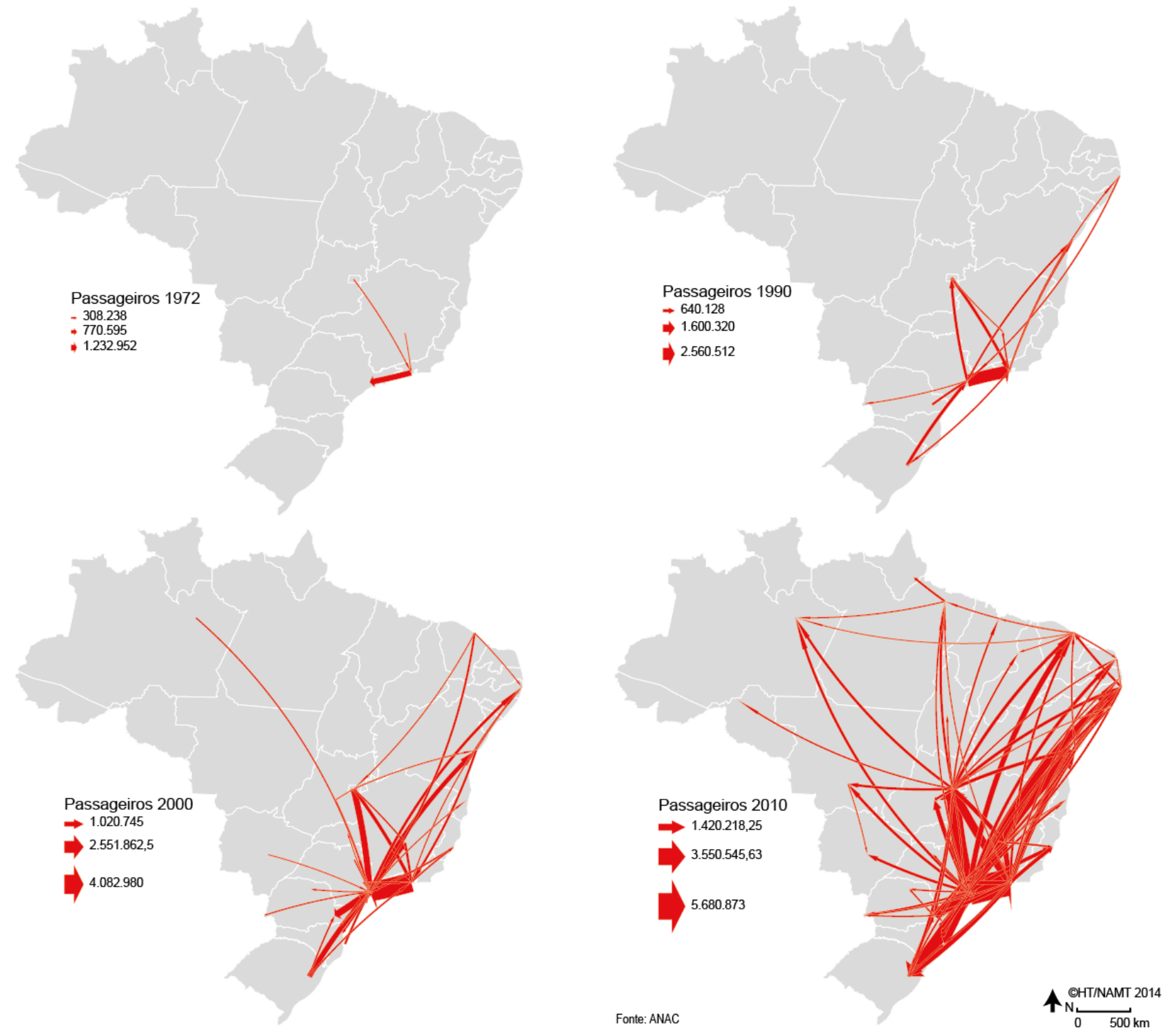

Finalmente, a Figura 5 mostra que a complexidade da rede atual é fruto de uma evolução que a fez passar de um embrião - principalmente a ponte aérea Rio de Janeiro - São Paulo - até uma cobertura relativamente completa - apesar de desigual - do território nacional. Para entender como e porquê e comparar com o caso europeu, remetemos o leitor às Referências que se seguem. 


\section{Referências}

GRASLAND, L.; THÉRY, H. La généralisation des transports aériens en Europe : saturation du centre et redéploiement vers la périphérie. Mappemonde, Montpellier, v. 94, n. 3 , p. 40-42, 1994. Disponível em: <http://www.mgm.fr/PUB/Mappemonde/M394/FLUXAERIEN.pdf>. Acesso em: 21 maio 2015.

IBGE. Instituto Brasileiro de Geografia e Estatística. Ligações Aéreas 2010: conexão de seis cidades com São Paulo absorve 25\% do transporte de passageiros. Censo 2010, 21 maio 2013.

PEREIRA, A. P. C. Asas da centralidade em céus conhecidos: a dinâmica empresarial do setor de transporte aéreo no território brasileiro. Tese (Doutorado em Geografia Humana) - Faculdade de Filosofia, Letras e Ciências Humanas, Universidade de São Paulo, 2014. Disponível em: <http://www.teses.usp.br/teses/disponiveis/8/8136/tde-06052015-145214/>. Acesso em: 21 maio 2015.

THÉRY, H. Os transportes aéreos no Brasil, ou as asas da centralidade. Mercator, Fortaleza, ano 2, n. 3, p. 19-29, 2003. Disponível em: <http://www.mercator.ufc.br/index.php/ mercator/article/view/160/128. Acesso em: 21 maio 2015. 